Vol. 4, No. 1, 2018

\author{
Vasyl Trush ${ }^{1}$, Alexander Luk'yanenko ${ }^{2}$ \\ ${ }^{1}$ Department of High Temperature Strength of Structural Materials in Gas and Liquid Metal Media, Karpenko \\ Physico-Mechanical institute of the NAS of Ukraine, 5, Naukova Str., Lviv, Ukraine, \\ E-mail: trushvasyl@gmail.com \\ ${ }^{2}$ Department of High Temperature Strength of Structural Materials in Gas and Liquid Metal Media, Karpenko \\ Physico-Mechanical institute of the NAS of Ukraine, 5, Naukova Str., Lviv, Ukraine, \\ E-mail: lukyanenko@ukrpost.ua
}

\title{
KINETICS OF HIGH-TEMPERATURE INTERACTION OF TITANIUM ALLOYS WITH A CARBON-CONTAINING GASEOUS MEDIUM
}

Received: April 18, 2018 / Revised: June 20, 2018 / Accepted: June 26, 2018

(C) Trush V., Luk'yanenko A., 2018

Abstract. Due to their excellent complex of physical, chemical, and mechanical properties, titanium alloys are unique materials for many branches of industry. An important feature of titanium is its high reactivity concerning the interstitial chemical elements (oxygen, nitrogen, and carbon). The absorption of interstitial elements by titanium alloys causes change in physical and mechanical properties of alloys and articles which are made of them. It should be noted that the titanium alloys are classified, in particular, by the compositions of their structures. Investigations of titanium alloys of different structural compositions will enable us to take into account the influence of their features on the kinetics of their interaction with interstitial elements.

Results of experimental investigations of the influence of a carbon-containing gaseous medium on the kinetics of interaction of titanium alloys of different structural classes ( $\alpha$-, pseudo- $\alpha$, and $(\alpha+\beta))$ are presented in this paper. It is established that the interaction at high temperatures $\left(T=750-850^{\circ} \mathrm{C}\right)$ of titanium alloys with rarefied carbon-containing gaseous medium (Ar+16.7 \% $\left.\mathrm{C}_{3} \mathrm{H}_{8}\right)$ under a pressure of $P=0.116 \mathrm{~Pa}$ leads to the increase in mass of the specimens according to a law which is close to linear dependence on time.

Keywords: titanium alloy, reactivity, absorption, structural composition, kinetics, interstitial element, gaseous medium, specimen.

\section{Introduction}

During the whole history of application of titanium alloys, the increase in their production and in volume of their application in different structures was more than once interrupted by sharp declines. The reasons for this were related to untimely awareness of peculiarities of titanium which concern its high reactivity concerning interstitial elements (oxygen, nitrogen, and carbon) [1-5], the solubility of which in titanium matrix leads to solid-state hardening.

In titanium alloys, interstitial elements are always present, at least in inconsiderable concentrations as impurities (undesirable substances). Therefore, the most important task of metallurgy of titanium was the reduction of concentration of interstitial elements in the initial metal; this ensures the workability (ductility, deformability, etc.) of semi-finished items made of titanium alloys. Nowadays, this task is successfully fulfilled. Besides, alloying with oxygen (less than $0.2 \%$ ) is used in modern economically alloyed titanium alloys [6]. At the same time, the solid-solution hardening of titanium alloys is a result of their interaction with oxygen, nitrogen, carbon during technological or operational heating, during thermal or chemical-thermal treatments. In these cases, there forms a surface diffusive (saturated with gas) layer of a certain depth with gradient of concentration of interstitial elements. Since the layer which is saturated with gas possesses higher hardness, it is also called $\alpha$-layer or hardened layer; i.e. there we deal with a socalled solid-solution hardening of near-surface layers of titanium alloys. The layer which is saturated with 
gas influences the operational properties of the article as a whole; therefore, when choosing regimes of thermal treatment (temperature-temporal, gas-dynamic parameters of the medium), it is necessary to take into account the interaction of titanium alloys with interstitial elements and to prognosticate the consequences of their influence on operational properties of articles.

\section{Problem formulation}

The interaction of titanium with interstitial elements combines different processes and reactions both in gaseous phase and at surface and in near-surface layer of metal: mass transfer in gaseous phase; adsorption of gas molecules at the surface or their desorption; degradation of adsorbed molecules and chemisorptions or recombination of adsorbed atoms into adsorbed molecules; transfer of adsorbed atoms through the surface of the metal or transition of dissolved atoms into adsorbed state; diffusion of gas atoms into the interior of the metal $[7,8]$. With the exception of the second stage, each of the successive stages of deepening of penetration can be controllable depending on the conditions of mass transfer in gaseous phase, deepening on the state of the surface, on temperature and the distribution of the concentration of the gas dissolved in the metal [8].

\section{Analysis of modern information sources on the subject of the paper}

According to the constitution diagram (phase diagram) of "titanium-carbon" system (Fig. 1) [9], carbon is soluble in $\alpha$ - and $\beta$-modifications of titanium in small amounts. The maximal solubility (Fig. 2) of carbon in $\alpha$-titanium amounts to $0.48 \pm 0.02 \%$ in mass; and in $\beta$-titanium it varies from $0.15 \%$ in mass at $920{ }^{\circ} \mathrm{C}$ to $0.86 \%$ in mass at $1750{ }^{\circ} \mathrm{C}$ [10]. However, under the pressure of oxygen and nitrogen in the system, its solubility increases [12]. Increasing the temperature of polymorphic transition of titanium to $920^{\circ} \mathrm{C}$, carbon somewhat extends the domain of $\alpha$-phase, since carbon is such an element which is $\alpha$ stabilizer.

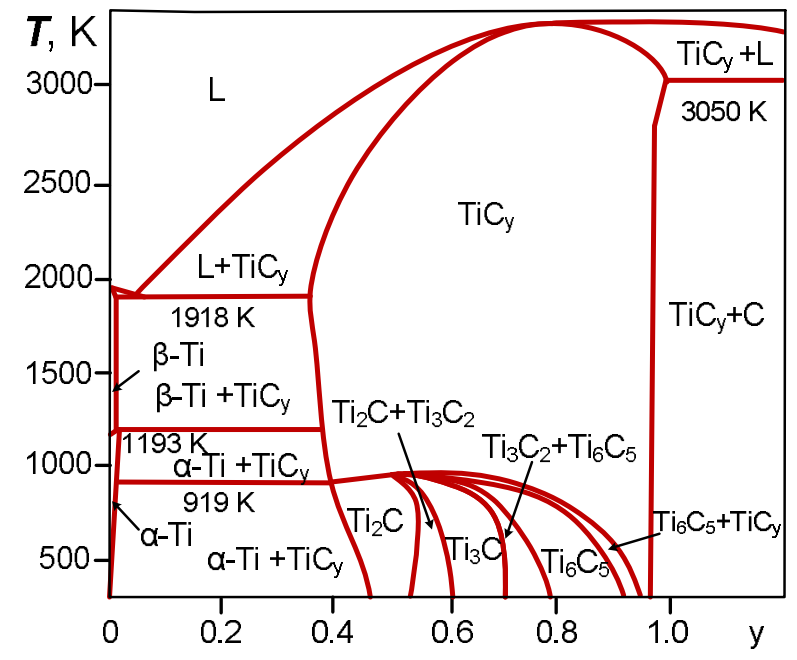

Fig. 1. "Titanium-carbon" constitution diagram [9]

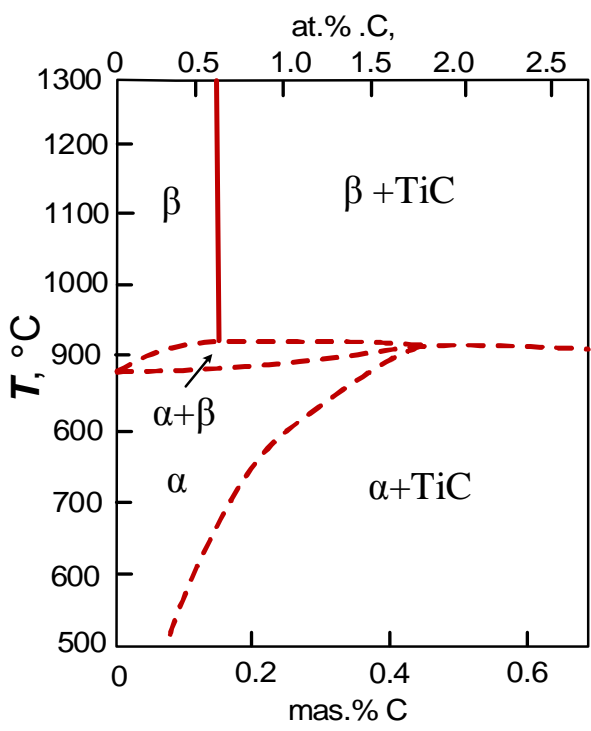

Fig. 2. Fragment of "titanium-carbon" constitution diagram [10]

Atoms of carbon take their places in octahedral cavities of hexagonal close-packed lattice of $\alpha$-titanium, and they form with $\alpha$-titanium only one kind of carbide phase - TiC monocarbide, which is characterized by vast region of homogeneity (from 11 to $20 \%$ at. or 33 to $50 \%$ at. at peritectical temperature). The presence of such a region is determined, in majority of cases, by defects of carbon sublattice. Under stoichiometric composition, the titanium carbide contains 13 to $20 \%$ in mass. $\%$ (37 to 50 at. \%) of titanium [9,10] and possesses high melting temperature (from 2940 to $3250{ }^{\circ} \mathrm{C}$ ) [11]. Usually, in TiC phase ideal stoichiometry is not observed. When crystallized into cubic system, titanium carbide is of face- 
centered cubic lattice (like $\mathrm{NaCl}$ ) with the lattice period of $a=0.4319-0.4328 \mathrm{~nm}[11,12]$. Carbon increases the periods of lattice of the solid solution on the basis of $\alpha$-phase of titanium, the period $c$ being increased more than the period $a$ [13].

The rates of formation and growth of carbide layers, as well as the compositions of their phases and their structures, are determined by the composition of the saturating medium, by activity of the latter, by temperature and duration of the saturating. The formation of carbide coating on titanium proceeds by way of formation of solid solution, i.e. according to the constitution diagram. This is related to the relationship of activation energies of the processes, because the activation energy of carbon diffusion in titanium with formation of solid solution in considerably less than that with formation if TiC carbide [14]. Since the crystal lattice of TiC carbide belongs to highly symmetric cubic lattices, for which there is a lack of predominant crystallographic directions, the rates of diffusion through all carbide layers is, practically, equal in the all the directions, and they depends only on the gradient of concentration. Since the latter is directed to the bulk of matrix, the stream of carbon atoms at all points of the formed carbide is uniformly distribution and directed to the matrix up to the boundary between phases; at the interphase boundary, there proceeds the reaction of carbide formation. This, in its turn, causes frontal growth of the layer, approximately uniform its thickness and relatively straight-lined boundary which divides phases [11, 15 and 16].

The thickness of carbon layers on titanium alloys is determined by not only activity of the medium, but also by the diffusive mobility of atoms of titanium and carbon [17]. In titanium carbide, the coefficient of diffusion of titanium is approximately by four decimal orders less than the coefficient of diffusion of carbon. The activation energy of self-diffusion of carbon in carbide increases with the increase in defectiveness in the carbide with respect to carbon; while the activation energy of titanium self-diffusion in $\mathrm{TiC}$ is of one and the same value for of compositions; i.e. it does not depend on the defectiveness of carbon sub-lattice, because atoms of metal diffuse only over vacancies of their own sub-lattice $[17,18]$.

The change in concentration of carbon in titanium-carbide over the whole region of homogeneity influences its properties; they depend on the non-metal (carbon) to metal (titanium) ratio and on the concentration of vacancies $[9,11$, and 18$]$.

It is also necessary to note that, due to the difference between the atomic radii of the interstitial elements $(0.077 \mathrm{~nm}$ for carbon, $0.075 \mathrm{~nm}$ for nitrogen, and $0.73 \mathrm{~nm}$ for oxygen), the modification of titanium with carbon, as compared to modification with nitrogen and to modification with oxygen, causes greater effect of surface hardening. The maximal surface microhardness which can be attained by means of carburizing, nitriding, and oxidation amounts to 32,20 , and $10 \mathrm{GPa}$, respectively; while for not-treated titanium it amounts to 3-4 GPa [16, 17, and 20]. However, due to poor solubility of carbon in titanium, as compared to nitrogen and, especially, oxygen, the diffusive layer after carburizing is not deep. Therefore, carbide coatings are characterized by sharp gradients of properties when passing through boundary between the matrix and the coating [21-23].

\section{Statement of purpose and problems of research}

The aim of this work is to establish the main laws of high-temperature interaction of titanium alloys of different structural compositions with carbon-containing gaseous medium.

\section{Experimental procedure and results}

It is know that titanium alloys are classified by their purpose, properties, and structural compositions [24]. Investigation of titanium alloys of different structural compositions will enable us to research in details the influence of structural peculiarities on formation of solid-solution hardening (strengthening) of near-surface layers. Therefore, there were investigated samples of $\alpha-$, pseudo- $\alpha-$, and $(\alpha+\beta)$-classes, the chemical composition of which is given in Table 1, in order to estimate the influence of the alloy's structure upon the character of interaction with carbon-containing medium.

The $\alpha$-alloys of titanium are those the structure of which after deformation and after subsequent annealing is $\alpha$-phase. The $\alpha$-alloys may contain $\mathrm{Al}, \mathrm{Sn}$, and $\mathrm{Zr}$ as alloying elements. The representatives of 
this class of alloys are industrially (commercially) pure BT1-0, the amount of impurities in which is within the range of their solubility in $\alpha$-phase, and the alloys BT5-16 ПТ-7M [24]. The advantages of $\alpha$-alloys are their good weldability, good foundry properties, absence of cold brittleness, high resistance to creeping, high thermal stability (absence of embrittlement after aging under stress), and moderate strength with satisfactory ductility.

Table 1

Chemical compositions of industrial titanium alloys (ГOCT 1980-91), mass \%

\begin{tabular}{|c|c|c|c|c|c|c|c|}
\hline \multirow{2}{*}{ Alloy } & \multirow{2}{*}{ Alloying elements } & \multicolumn{5}{|c|}{ Impurities, no more than } \\
\cline { 3 - 8 } & & $\mathrm{C}$ & $\mathrm{Fe}$ & $\mathrm{Si}$ & $\mathrm{O}$ & $\mathrm{N}$ & $\mathrm{H}$ \\
\hline BT1-0 & - & 0.07 & 0.20 & 0.10 & 0.12 & 0.04 & 0.01 \\
\hline BT5-1 & $5.0 \mathrm{Al}$ & 0.10 & 0.30 & 0.12 & 0.20 & 0.015 & 0.015 \\
\hline חT-7M & $1.8-2.5 \mathrm{Al} ; 2.0-3,0 \mathrm{Zr}$ & 0,10 & 0.25 & 0.12 & 0.15 & 0.04 & 0.006 \\
\hline OT4-1 & $3.5-5.0 \mathrm{Al} ; 0.8-2.0 \mathrm{Mn}$ & 0,10 & 0.30 & 0.15 & 0.15 & 0.05 & 0.012 \\
\hline BT14 & $3.5-6.3 \mathrm{Al} ; 2.5-3.8 \mathrm{Mo} ; 0.9-1.9 \mathrm{~V}$ & 0,10 & 0.30 & 0.15 & 0.15 & 0.05 & 0.015 \\
\hline BT19 & $2.5-3.5 \mathrm{Al} ; 5,0-6.0 \mathrm{Mo} ; 4.0-5.0 \mathrm{Cr} ; 0.5-1.5 \mathrm{Zr}$ & 0.10 & 0.30 & 0.15 & 0.15 & 0.05 & 0.015 \\
\hline
\end{tabular}

The pseudo- $\alpha$ - alloy OT4- 1 is an alloy on the basis of $\alpha$-titanium which in its stable state contains $2-6 \%$ of $\beta$-phase [24]. The amount of $\beta$-phase in pseudo- $\alpha$-alloys is such that they, besides all the main properties and advantages of single-phase $\alpha$-alloys, possesses also some mew good qualities which distinguish the alloys of this class from $\alpha$-alloys. These alloys practically do not accept hardening (strengthening) thermal treatment.

The two-phase $(\alpha+\beta)$-alloys of martensite type contain considerable amount of $\beta$-stabilizing elements (from 5 to $25 \%$ of $\beta$-phase) in their stable state, but not more than critical concentration. The alloy BT14 belongs to this group of alloys.

The alloy BT19 of Ti-Al-V-Mo-Zr system, whose coefficient of $\beta$-stabilization is 1.45 ([Mo] equivalent $=17.2 \%$ ), possesses a good complex of technological and mechanical properties. It is rather adaptable both to hot working and clod plastic working. When in hardened (strengthened) and annealed state, it does not possess high strength. In the course of aging, its properties of strength can be considerably heightened: up to $\sigma=1550-1700 \mathrm{MPa}, \delta=3-6 \%$.

After their manufacturing, the specimens for formation of initial phase-structural state (relief of residual stresses, removal of hydrogen, homogenization, and stabilization of structure) were annealed in vacuum under the following regime: $T=800{ }^{\circ} \mathrm{C}, \tau=5$ hours, $P=0.005 \mathrm{mPa}, I=0.1 \mathrm{mPa} \cdot \mathrm{dm}^{3} \cdot \mathrm{s}^{-1}$. In their initial state, the strength and ductility of their investigated alloy were the following: BT1-0 $-\sigma=450 \mathrm{MPa}$, $\delta=27 \%$; BT5 $-\sigma=895 \mathrm{MPa}, \delta=20 \%$; ПТ-7M $-\sigma=550 \mathrm{MPa}, \delta=24 \%$; OT4-1 $-\sigma=655 \mathrm{MPa}$, $\delta=21.5 \%$.

For thermal treatment of titanium alloys, the plant for annealing in vacuum and in controllable gaseous media which had been developed in Karpenko Physico-Mechanical institute of the NAS of Ukraine was used. As the carbureting medium, there was used a mixture of argon and propane. The propane content amounted to $16.7 \%$ by volume.

The scheme of the regime of carbureting the titanium alloys is presented in Fig. 3. The specimens of titanium alloys were heated in vacuum of $26.6 \mathrm{mPA}$ to the temperature of saturation; upon reaching the temperature of saturation $\left(T=750{ }^{\circ} \mathrm{C}, 800{ }^{\circ} \mathrm{C}, 850{ }^{\circ} \mathrm{C}\right)$, the gas mixture $\left(\mathrm{Ar}+16.7 \% \mathrm{C}_{3} \mathrm{H}_{8}\right)$ was fed into the reaction chamber, the pressure of which is kept at the level of $P\left(\mathrm{Ar}+\mathrm{C}_{3} \mathrm{H}_{8}\right)=0.106 \mathrm{~Pa}$ at the expense of continuous its feeding (inflow); the partial pressure $P_{\mathrm{C} 3 \mathrm{H} 8}$ of propane amounted to $18 \mathrm{mPa}$. The constant concentration of saturating component $\left(\mathrm{C}_{3} \mathrm{H}_{8}\right)$ was being ensured by continuous supply of carboncontaining gas mixture. On termination of saturating holding, whose duration $\tau=1-5$ hours, the chamber was evacuated, and the specimens were cooled together with the furnace. After the cooling, the reaction chamber was dehermetized, and the specimens were taken out for further researches. 


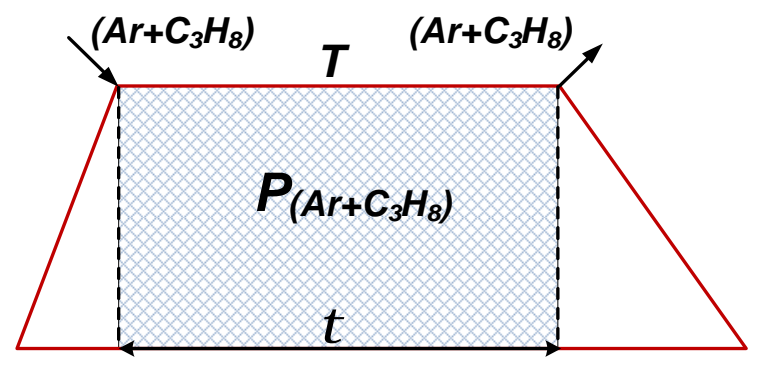

Fig. 3. Scheme of regime of carburization of titanium alloys in rarefied gaseous medium $\left(\mathrm{Ar}+16.7 \% \mathrm{C}_{3} \mathrm{H}_{8}\right)$

During high-temperature interaction of titanium alloys with technological media which can contain oxygen, nitrogen, and carbon, there takes place (according to the thermochemical calculations) the predomination (over interaction with carbon and formation of titanium carbide) of processes of oxidation and nitriding of titanium (Fig. 4, a); even under reduction of pressure of gaseous components of the medium, oxidation and nitriding predominate (Fig. 4, b). Therefore, for interaction of titanium alloys predominantly with carbon, we have chosen oxygen- and nitrogen-free gaseous medium consisting of argon and propane $\left(\mathrm{C}_{3} \mathrm{H}_{8}\right)$. Since the energy of formation of interstitial solid solution is somewhat greater than that of formation of the corresponding compounds, in order to decelerate the kinetic factor and for domination of formation of diffusion layer (solid solution) of carbon in titanium, we saturated the titanium alloys in rarefied stream of $\left(\mathrm{Ar}+16.7 \% \mathrm{C}_{3} \mathrm{H}_{8}\right)$ gas mixture with the pressure of $P=0.106 \mathrm{~Pa}$ at temperatures of $T=750{ }^{\circ} \mathrm{C}, 800^{\circ} \mathrm{C}$, and $850{ }^{\circ} \mathrm{C}$ for 1 hour, 3 hours, and 5 hours.

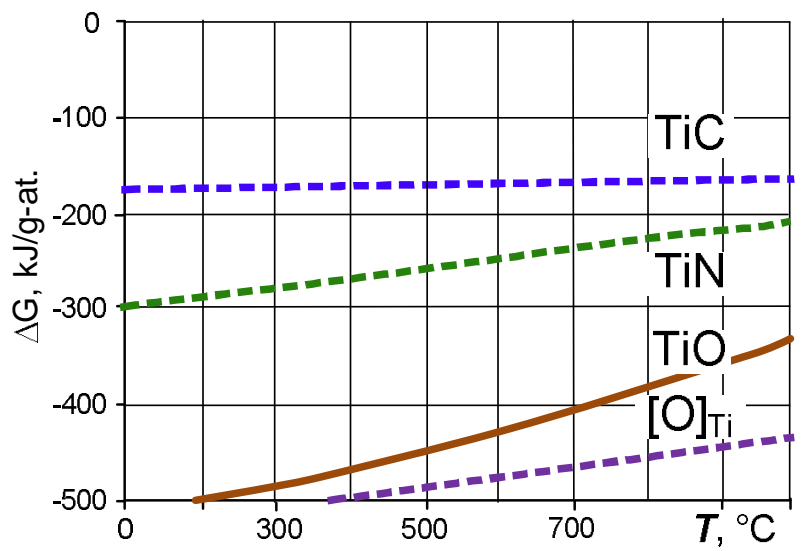

$a$

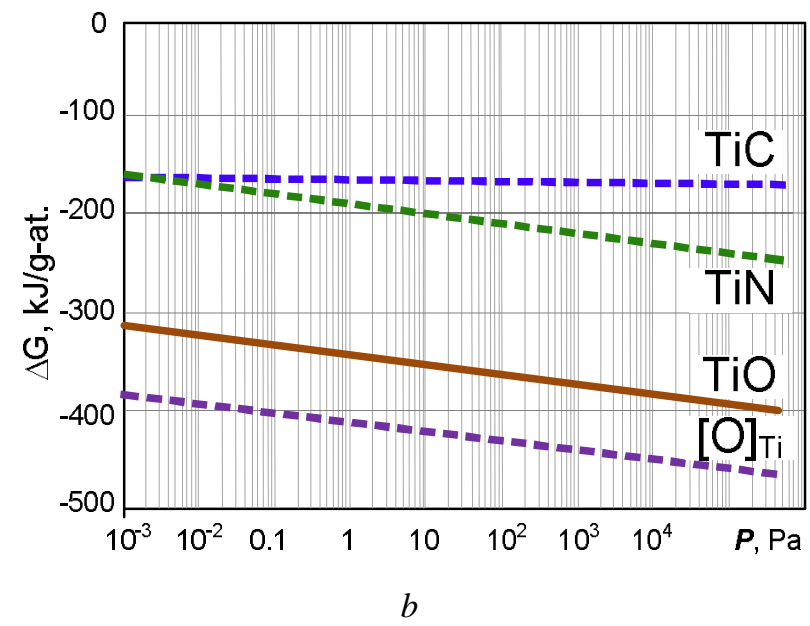

$b$

Fig. 4. Isobaric-isothermal potential of chemical compounds formation depending on (a) temperature at normal pressure and (b) on pressure of gaseous medium at $T=750{ }^{\circ} \mathrm{C}$

Analysis of results of calculation of change isobaric-isothermal potential of formation of propane from carbon and hydrogen indicate that heating the propane under normal $(1 \mathrm{~atm}$.) pressure causes its degradation at temperatures of $\boldsymbol{T} \geq 800{ }^{\circ} \mathrm{C}$ (Fig. 5 curve 1); and the reduction of its partial pressure to $\boldsymbol{p}_{\mathrm{C} 3 \mathrm{H} 8}=0.018 \mathrm{~Pa}$, which is under the conditions of the experiment, leads to degradation of propane as early as at a temperature of $\boldsymbol{T} \geq 320^{\circ} \mathrm{C}$ (Fig. 5, curve 2).

With the increase in partial pressure of propane at the aforesaid temperatures, there is observed formation of phase film of titanium carbide (TiC) at the surfaces of titanium alloys.

\section{Kinetics of change in mass of the $\alpha$-titanium alloys BT1-0, BT5, and ПT-7M}

In the course of interaction of $\alpha$-titanium alloys with rarefied carbon-containing gaseous medium under high temperatures $\left(T=750{ }^{\circ} \mathrm{C}, 800^{\circ} \mathrm{C}\right.$, and $\left.850^{\circ} \mathrm{C}\right)$ for 1,3 , and 5 hours, the mass of the specimens increases (Fig. 6). 
Analysis of gravimetric data which had been obtained by means of discrete gravimetry has indicated that due to the treatment in argon-propane mixture at a pressure of $P=0.106 \mathrm{~Pa}$ under different temperatures the mass of the specimens of BT1-0 alloy increases according to linear dependence (Fig. 6). This dependence is valid when the rate of gas absorption is controlled by reaction at the interface of the phases: this is possible if the rate of gas penetration through the metal surface is sufficiently high, for example, under the absence of surface phase film or if the film is porous.

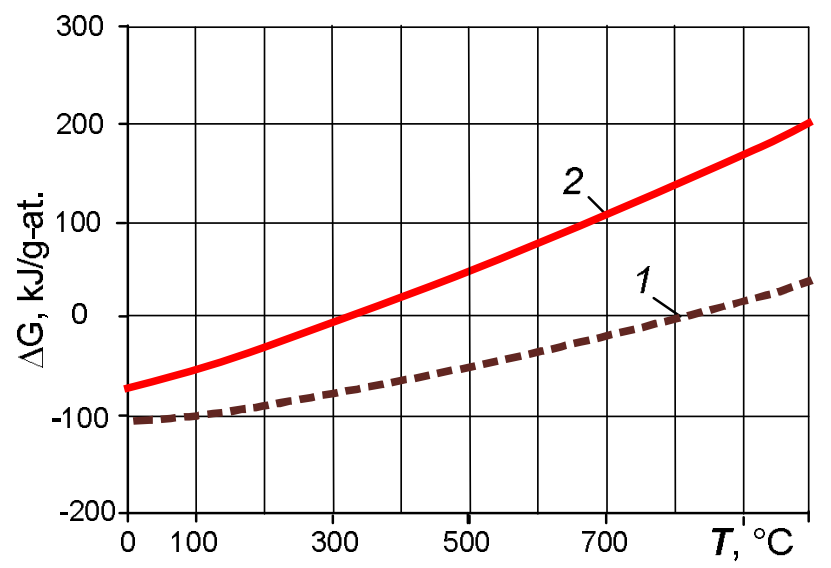

Fig. 5. Dependence of isobaric-isothermal potential of propane formation on temperatures at different pressures of propane: $1-10100 \mathrm{~Pa} ; 2-0.018 \mathrm{~Pa}$

The kinetics of saturation of BT5-1 alloy with carbon has considerable deviations from linearity. For example, the values of mass-increase of BT5-1 alloy after its 5 hours exposure to carbon-containing medium is two times less than that for BT1-0 alloy.

There is also deviation from linearity in the change of mass of specimens of ПТ-7M alloy, but the difference of the values of mass increase after 5-hour exposure as compared with BT5-1 alloys is less. Such distinction can be accounted for by the influence of alloying elements on processes of absorption and diffusion of carbon in these alloys.
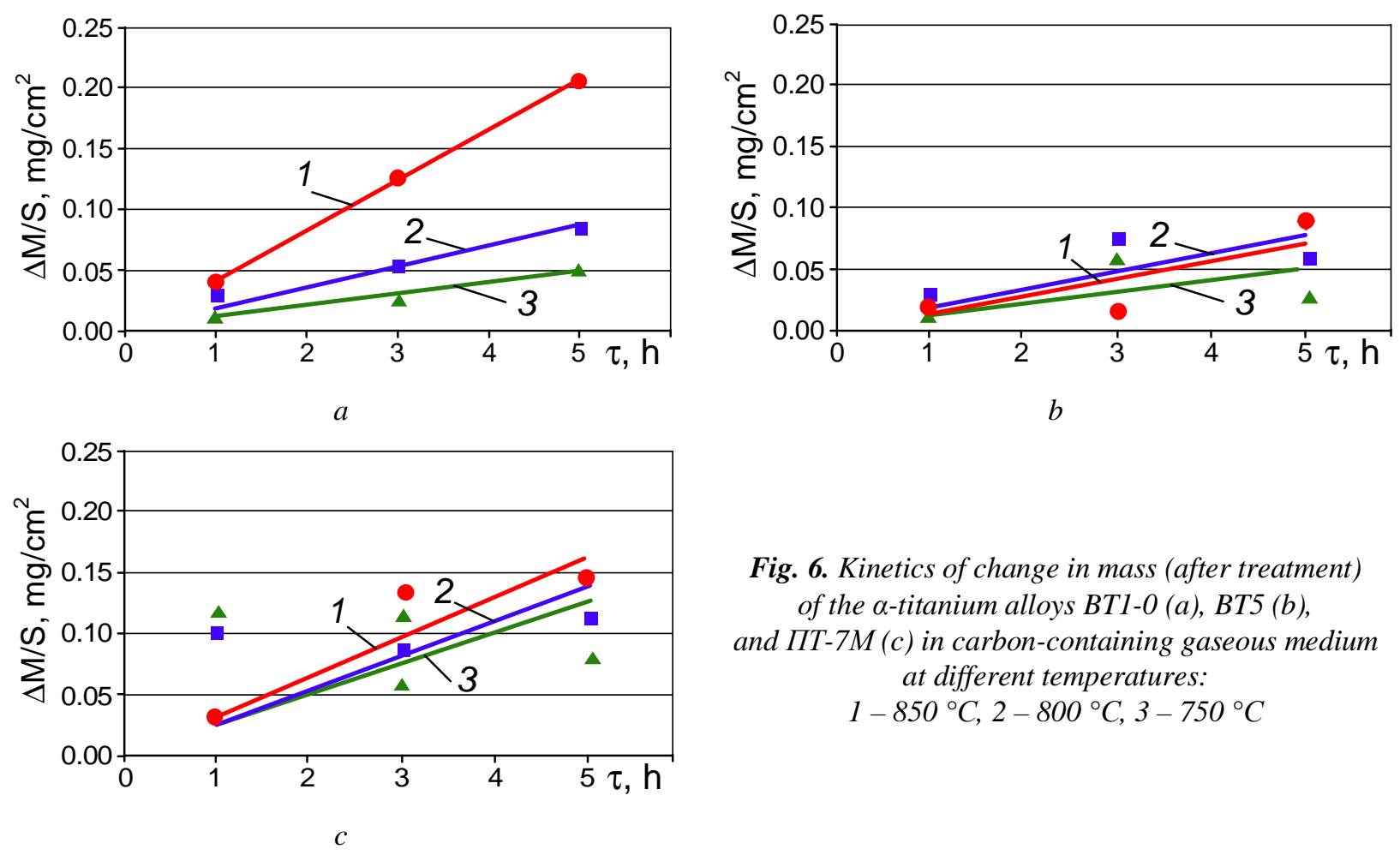

Fig. 6. Kinetics of change in mass (after treatment) of the $\alpha$-titanium alloys BT1-0 (a), BT5 (b), and $\Pi T-7 M(c)$ in carbon-containing gaseous medium at different temperatures: $1-850{ }^{\circ} \mathrm{C}, 2-800^{\circ} \mathrm{C}, 3-750{ }^{\circ} \mathrm{C}$ 
The kinetic dependences of interaction of $\alpha$-titanium alloy with argon-propane gas mixture at a residual pressure of $P=0.106 \mathrm{~Pa}$ within 5-hour interval are satisfactorily described by the linear dependence:

$$
\Delta m / S=\left(K^{p} \times \tau \pm A\right),\left[\mu \mathrm{g} / \mathrm{cm}^{2}\right],
$$

where $K^{p}$ is the coefficient of linear rate under constant pressure; $\tau$ is the time (in hours); $A$ is the confidence interval with 0.98 probability.

The coefficient of linear rate under constant pressure (under isobaric conditions) of thermally active process depends on the absolute temperature $\boldsymbol{T}$ according to the Arrhenius equation:

$$
K^{P}(T)=B \times \exp \left(-E_{\text {ext }} / R T\right) \pm C,\left[\mathrm{mg} \cdot \mathrm{cm}^{2} \cdot \text { hour }^{-1}\right],
$$

where $B$ is the constant which depends on temperature; $E_{\text {ext }}$ is the total energy of activation of the process; $\mathrm{C}$ is the confidence interval with 0.98 probability. The constants for formulas (1) and (2) as well as the values of experimental energy of activation of process are presented in Table 2.

Table 2

\begin{tabular}{|c|c|c|c|c|c|c|}
\hline \multirow{3}{*}{ Alloy } & \multirow{3}{*}{$T,{ }^{\circ} \mathrm{C}$} & \multicolumn{5}{|c|}{ For $P=0.106 \mathrm{~Pa}$} \\
\hline & & \multicolumn{2}{|c|}{ According to Formula (1) } & \multicolumn{3}{|c|}{ According to Formula (2) } \\
\hline & & $\begin{array}{c}K^{P} \\
\mathrm{mg} \cdot \mathrm{cm}^{2} \cdot \mathrm{hour}^{-1}\end{array}$ & $\begin{array}{c}A, \\
\mathrm{mg} \cdot \mathrm{cm}^{2}\end{array}$ & $\begin{array}{c}B, \\
\mathrm{mg} \cdot \mathrm{cm}^{2} \cdot \text { hour }^{-1}\end{array}$ & $\begin{array}{c}E_{\mathrm{ext}}, \\
\mathrm{J} \cdot \mathrm{mol}^{-1}\end{array}$ & $\begin{array}{c}C, \\
\mathrm{mg} \cdot \mathrm{cm}^{2} \cdot \text { hour }^{-1}\end{array}$ \\
\hline \multirow{3}{*}{ BT1-0 } & 750 & 0.0097 & 0.0004 & \multirow{3}{*}{$97.133 \times 10^{3}$} & \multirow{3}{*}{137724} & \multirow{3}{*}{0.005} \\
\hline & 800 & 0.0172 & 0.0007 & & & \\
\hline & 850 & 0.0412 & 0.0016 & & & \\
\hline \multirow{3}{*}{ BT5-1 } & 750 & 0.0146 & 0.0005 & \multirow{3}{*}{$17.2 \times 10^{-3}$} & \multirow{3}{*}{2572} & \multirow{3}{*}{0.004} \\
\hline & 800 & 0.0097 & 0.0003 & & & \\
\hline & 850 & 0.0152 & 0.0010 & & & \\
\hline \multirow{3}{*}{ ПТ-7М } & 750 & 0.0260 & 0.0010 & \multirow{3}{*}{$359.5 \times 10^{-3}$} & \multirow{3}{*}{22550} & \multirow{3}{*}{0.001} \\
\hline & 800 & 0.0273 & 0.0008 & & & \\
\hline & 850 & 0.0330 & 0.0011 & & & \\
\hline
\end{tabular}

Kinetic parameters of saturation with carbon for $\alpha$-titanium alloys
under isobaric conditions of argon-propane gas mixture

The dissolution of carbon in near-surface layers of $\alpha$-titanium alloys is accompanied by change in their crystal lattices, which are recorded by X-ray diffraction analysis (Table 3).

Table 3

\begin{tabular}{|c|c|c|c|c|c|c|c|c|c|c|c|}
\hline \multirow{3}{*}{ Alloy } & \multirow{3}{*}{$\begin{array}{c}\text { Para-meter } \\
\text { of lattice }\end{array}$} & \multicolumn{10}{|c|}{ Parameters of the lattice ( $\AA$ ) for exposition at temperature $T$ and duration $\tau$} \\
\hline & & \multirow{2}{*}{$\begin{array}{c}\text { Initial } \\
\text { state }\end{array}$} & \multicolumn{3}{|c|}{$750{ }^{\circ} \mathrm{C}$} & \multicolumn{3}{|c|}{$800^{\circ} \mathrm{C}$} & \multicolumn{3}{|c|}{$850^{\circ} \mathrm{C}$} \\
\hline & & & 1 hour & 3 hour & 5 hour & 1 hour & 3 hour & 5 hour & 1 hour & 3 hour & 5 hour \\
\hline \multirow{3}{*}{ BT1-0 } & $a$ & 2.9481 & 2.9550 & 2.9511 & 2.9500 & 2.9490 & 2.9495 & 2.9500 & 2.9500 & 2.9552 & 2.9565 \\
\hline & $c$ & 4.6842 & 4.6950 & 4.6960 & 4.6970 & 4.6950 & 4.6980 & 4.6995 & 4.6875 & 4.6963 & 4.6995 \\
\hline & $c / a$ & 1.5889 & 1.5888 & 1.5913 & 1.5922 & 1.5921 & 1.5928 & 1.5931 & 1.5890 & 1.5892 & 1.5895 \\
\hline \multirow{3}{*}{ BT5-1 } & $a$ & 2.9286 & 2.9353 & 2.9300 & 2.9308 & 2.9290 & 2.9334 & 2.9350 & 2.9340 & 2.9372 & 2.9380 \\
\hline & $c$ & 4.6743 & 4.6863 & 4.6880 & 4.6912 & 4.6814 & 4.6914 & 4.6940 & 4.6870 & 4.6973 & 4.6976 \\
\hline & $c / a$ & 1.5961 & 1.5965 & 1.6000 & 1.6007 & 1.5983 & 1.5993 & 1.5993 & 1.5975 & 1.5992 & 1.5989 \\
\hline \multirow{3}{*}{ ПТ7-М } & $a$ & 2.9484 & 2.9513 & 2.9468 & 2.9479 & 2.9485 & 2.9490 & 2.9500 & 2.9486 & 2.9488 & 2.9489 \\
\hline & $c$ & 4.6934 & 4.6980 & 4.6982 & 4.6990 & 4.6950 & 4.6965 & 4.6995 & 4.6963 & 4.6980 & 4.6983 \\
\hline & $c / a$ & 1.5918 & 1.5918 & 1.5943 & 1.5940 & 1.5923 & 1.5926 & 1.5931 & 1.5927 & 1.5932 & 1.5932 \\
\hline
\end{tabular}

Change of parameters of crystal lattice of the titanium alloys BT1-0 BT5-1, ПT7-M

As it is indicated by the results, the deviation of the parameters $a$ and $c$ of Hexagonal Close Packed (HCP) lattice of $\alpha$-titanium proceeds in different ways, but in any way the ratio $c / a$ of axes increases, this indicates the increase in amount of carbon dissolved in titanium [8]. 


\section{Kinetics of change in mass of OT4-1 pseudo $\alpha$-titanium alloy}

The interaction of OT4-1 pseudo $\alpha$-titanium alloy with a rarefied carbon containing gaseous medium at high temperatures $\left(T=750,800\right.$, and $850{ }^{\circ} \mathrm{C}$ ) is accompanied by loss in mass of samples (specimens) (Fig. 7), this is accounted for by the sublimation of $\mathrm{Mn}$ in the rarefied dynamic gaseous medium.

The peculiarity is the fact that at the temperatures of $T=750$ and $800{ }^{\circ} \mathrm{C}$ there is recorded loss of mass of the samples (specimens) during their exposition in argon-propane mixture (Fig. 7); this indicates the fact that the decrease in mass caused by sublimation predominates its increase caused by saturation with carbon.

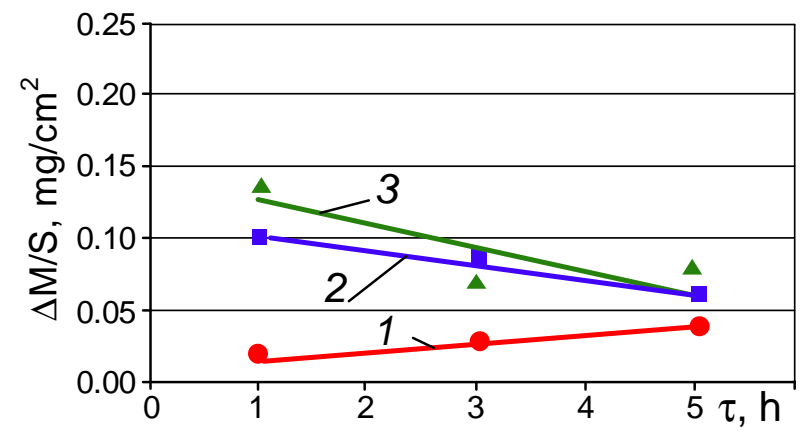

Fig. 7. Kinetics of change in mass of specimens of OT4-1 titanium alloys in carbon-containing gaseous medium under different temperatures: $1-850^{\circ} \mathrm{C}, 2-800^{\circ} \mathrm{C}, 3-750^{\circ} \mathrm{C}$

At the temperature of $850^{\circ} \mathrm{C}$, the loss of mass took place during the heating of the specimens in vacuum, and in argon-propane gas mixture there took place monotonous increase in mass of the specimens; this indicates the prevailing of saturation with carbon over sublimation (of $\mathrm{Mn}$ ).

Kinetics parameters of saturation of OT4-1 alloy with carbon under isobaric condition of rarefied argon-propane gas mixture (Table 4) have been experimentally established. It should be noted that under the chosen pressure of the saturation gaseous medium the dependence of the coefficient of linear rate under constant pressure (under isobaric condition) on the absolute temperature $T$ cannot be described by the Arrhenius' equation.

Table 4

Kinetics parameters of saturation with carbon for OT4-1 titanium alloys under isobaric conditions in argon-propane gas mixture

\begin{tabular}{|c|c|c|c|}
\hline \multirow{2}{*}{ Alloy } & \multirow{2}{*}{$T,{ }^{\circ} \mathrm{C}$} & \multicolumn{2}{|c|}{ For $P=0.106 \mathrm{~Pa}$} \\
\cline { 3 - 4 } & & $K^{P}, \mathrm{mg} \cdot \mathrm{cm}^{2} \cdot \mathrm{hour}^{-1}$ & $A, \mathrm{mg} \cdot \mathrm{cm}^{2}$ \\
\cline { 3 - 4 } & 750 & -0.0211 & 0.005 \\
\hline \multirow{3}{*}{ OT4-1 } & 800 & -0.0136 & 0.007 \\
\cline { 2 - 4 } & 850 & 0.0077 & 0.006 \\
\cline { 2 - 4 } & & & \multicolumn{2}{|c|}{ According to Formula (1) } \\
\hline
\end{tabular}

Because of near-surface saturation of a layer with carbon, parameters of crystal lattice of OT4-1 titanium alloy change (Table 5).

Analogically to $\alpha$-titanium alloys, the increase in the ratio $c / a$ of axes of HCP lattice indicates the increase in the amount of carbon dissolved in the near-surface layer of metal.

\section{Kinetics of change in mass of BT14 and BT19 two-phase $(\alpha+\beta)$-titanium alloys}

The interaction of BT14 and BT19 titanium alloys with a carbon-containing gaseous medium at the residual pressure of $P=0.106 \mathrm{~Pa}$ is characterized by increase in mass of the samples (specimens) under the temperatures and durations of the investigation (Fig. 8). The kinetics of the interaction of BT14 alloy is 
close to (approaches) that which corresponds to BT1-0 alloy. The kinetics of the interaction of BT19 is distinguished by loss in mass of the samples (specimens) during their heating in vacuum.

Table 5

Change of parameters of crystal lattice of the OT4-1 titanium alloy in the course of interaction with rarefied gas medium

\begin{tabular}{|c|c|c|c|c|}
\hline \multicolumn{2}{|c|}{ Regime of thermal-chemical treatment } & \multicolumn{2}{c|}{ Parameter. $\AA$} & \multirow{2}{*}{$c / a$} \\
\hline Temperature, $T$ & Duration, $\tau$ & $a$ & $c$ & \\
\hline \multirow{2}{|c|}{ Initial state } & & 2.9452 & 4.6850 & 1.5907 \\
\hline \multirow{3}{*}{$750{ }^{\circ} \mathrm{C}$} & 1 hour & 2.9460 & 4.6880 & 1.5913 \\
\cline { 2 - 4 } & 3 hours & 2.9489 & 4.6980 & 1.5931 \\
\cline { 2 - 4 } & 5 hours & 2.9490 & 4.7000 & 1.5938 \\
\hline \multirow{3}{*}{$800{ }^{\circ} \mathrm{C}$} & 1 hour & 2.9464 & 4.6880 & 1.5911 \\
\cline { 2 - 5 } & 3 hours & 2.9470 & 4.6910 & 1.5918 \\
\cline { 2 - 5 } & 5 hours & 2.9490 & 4.6962 & 1.5925 \\
\hline \multirow{3}{*}{$850{ }^{\circ} \mathrm{C}$} & 1 hour & 2.9456 & 4.6870 & 1.5912 \\
\cline { 2 - 5 } & 3 hours & 2.9459 & 4.6900 & 1.5920 \\
\cline { 2 - 5 } & 5 hours & 2.9460 & 4.6950 & 1.5937 \\
\hline
\end{tabular}

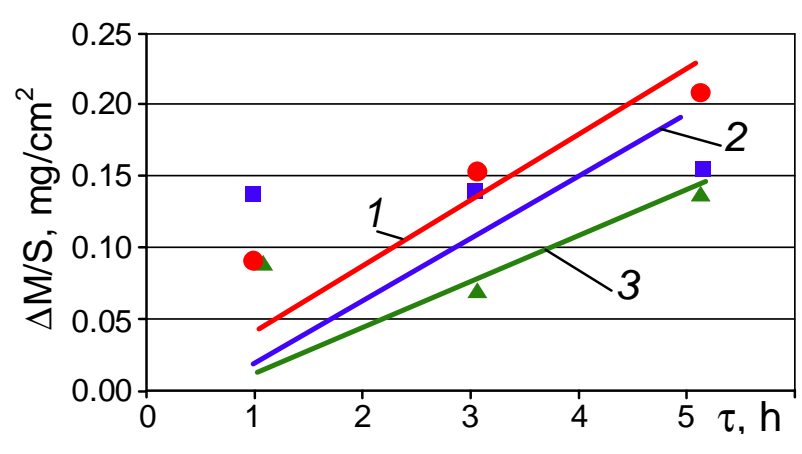

$a$

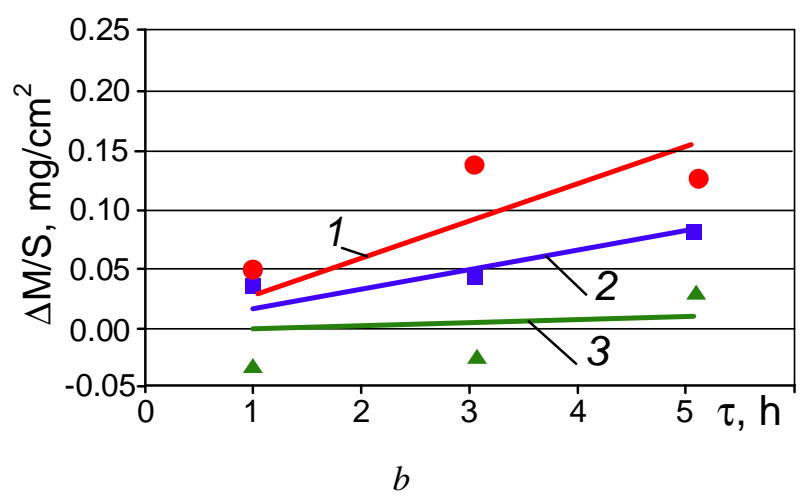

Fig. 8. Kinetics of change of mass of specimens of (a) BT14 and (b) BT19 titanium alloys in argon-propane mixture at $P=0.106 \mathrm{~Pa}$ under different temperatures: $1-850^{\circ} \mathrm{C} ; 2-800^{\circ} \mathrm{C} ; 3-750^{\circ} \mathrm{C}$

The kinetic parameters of saturation of $(\alpha+\beta)$ - titanium alloys by carbon under isobaric conditions of argon-propane gas mixture, according to the formulae (1) and (2), are persecuted in Table 6.

Table 6

Kinetic parameters of saturation of BT14 and BT19 $(\alpha+\beta)$-titanium alloys

by carbon under isobaric conditions in argon-propane gas mixture

\begin{tabular}{|c|c|c|c|c|c|c|}
\hline \multirow{3}{*}{ Alloy } & \multirow{3}{*}{$T,{ }^{\circ} \mathrm{C}$} & \multicolumn{5}{|c|}{ For $P=0.106 \mathrm{~Pa}$} \\
\hline & & \multicolumn{2}{|c|}{ According to Formula (1) } & \multicolumn{3}{|c|}{ According to Formula (2) } \\
\hline & & $\begin{array}{c}K^{P} . \\
m g \cdot \mathrm{cm}^{2} \cdot \text { hour }^{-1}\end{array}$ & $\begin{array}{c}A . \\
M g \times \mathrm{Cm}^{-2}\end{array}$ & $\begin{array}{c}B . \\
m g \cdot \mathrm{cm}^{2} \cdot \text { hour }^{-1}\end{array}$ & $\begin{array}{c}E_{\text {ext }} \\
\mathrm{J} \cdot \mathrm{mol}^{-1}\end{array}$ & $\begin{array}{c}C . \\
m g \cdot \mathrm{cm}^{2} \cdot h o u r^{-1}\end{array}$ \\
\hline \multirow{3}{*}{ BT14 } & 750 & 0.026 & 0.0004 & \multirow{3}{*}{17.329} & \multirow{3}{*}{55020} & \multirow{3}{*}{0.006} \\
\hline & 800 & 0.039 & 0.0007 & & & \\
\hline & 850 & 0.0461 & 0.0016 & & & \\
\hline \multirow{3}{*}{ BT19 } & 750 & 0.026 & 0.0005 & \multirow{3}{*}{$126.2 \times 10^{-3}$} & \multirow{3}{*}{14890} & \multirow{3}{*}{0.003} \\
\hline & 800 & 0.0166 & 0.0003 & & & \\
\hline & 850 & 0.0309 & 0.0010 & & & \\
\hline
\end{tabular}

The dissolution of carbon in near-surface layer of BT14 and BT19 titanium alloys leads to change in parameters of the crystal lattice of titanium (Table 7). 


\section{Change in parameters of crystal lattice of titanium in BT14 and BT19 alloys as result of interaction with rarefied carbon-containing gaseous medium}

\begin{tabular}{|c|c|c|c|c|c|c|c|c|c|c|c|}
\hline \multirow{3}{*}{ Alloy } & \multirow{3}{*}{$\begin{array}{l}\text { Para- } \\
\text { meters } \\
\text { of lattice }\end{array}$} & \multicolumn{10}{|c|}{ Parameters of the lattice $(\AA)$} \\
\hline & & \multirow{2}{*}{$\begin{array}{l}\text { Initial } \\
\text { state }\end{array}$} & \multicolumn{3}{|c|}{$750^{\circ} \mathrm{C}$} & \multicolumn{3}{|c|}{$800^{\circ} \mathrm{C}$} & \multicolumn{3}{|c|}{$850^{\circ} \mathrm{C}$} \\
\hline & & & 1 hour & 3 hours & 5 hours & 1 hour & 3 hours & 5 hours & 1 hour & 3 hours & 5 hours \\
\hline \multirow{3}{*}{ BT14 } & $a$ & 2.9360 & 2.9369 & 2.9360 & 2.9344 & 2.9367 & 2.9340 & 2.9335 & 2.9350 & 2.9350 & 2.9349 \\
\hline & $c$ & 4.6800 & 4.6825 & 4.6830 & 4.6850 & 4.6829 & 4.6840 & 4.6852 & 4.6810 & 4.6835 & 4.6864 \\
\hline & $c / a$ & 1.5940 & 1.5944 & 1.5950 & 1.5966 & 1.5946 & 1.5965 & 1.5971 & 1.5949 & 1.5957 & 1.5968 \\
\hline \multirow{3}{*}{ BT19 } & $a$ & 2.9421 & 2.9390 & 2.9385 & 2.9390 & 2.9442 & 2.9421 & 2.9390 & 2.9484 & 2.9442 & 2.9450 \\
\hline & $c$ & 4.6829 & 4.6885 & 4.6945 & 4.6970 & 4.6863 & 4.6870 & 4.6875 & 4.6969 & 4.6965 & 4.6990 \\
\hline & $c / a$ & 1.5917 & 1.5953 & 1.5976 & 1.5982 & 1.5917 & 1.5931 & 1.5949 & 1.5930 & 1.5952 & 1.5956 \\
\hline
\end{tabular}

Like for the aforesaid (previously mentioned) titanium alloys, the increase in the ratio $c / a$ of axes of hexagonal close-packed lattice indicates the increase in the amount of carbon dissolved in near-surface layer of metal. The increase in the ratio $c / a$ for $(\alpha+\beta)$-titanium alloys is greater than that for the previous ones; this can be accounted for by extra deviation (distortion) caused by $\beta$-stabilizing elements within the range of solubility of $\alpha$-titanium.

\section{Conclusions}

The influence of chemical-thermal treatment in a carbon-containing gaseous medium at different parameters (temperatures $T=750,800$, and $850^{\circ} \mathrm{C}$; durations $\tau=1,3$, and 5 hours) on kinetics of mass change of titanium alloys of different structural classes has been experimentally investigated. It has been established that high-temperature interaction $\left(T=750-850^{\circ} \mathrm{C}\right)$ of titanium alloys with a rarefied carbon-containing gaseous medium $\left(\mathrm{Ar}+16.7 \% \mathrm{C}_{3} \mathrm{H}_{8}\right)$ at the pressure of $P=0.106 \mathrm{~Pa}$ leads to the increase in mass of the samples (specimens) according to a dependence which is close to linear law; this indicates that the reactions at "gasmetal" determine the amount of carbon which is dissolved in near-surface layer. High temperature interaction of titanium alloys with a carbon-containing gaseous medium is accompanied by deviation of parameters of the crystal lattice of the hardened layers of a titanium alloys due to diffusion dissolution of carbon. Carburization seems to influence physical-chemical properties of the near-surface layer of metal.

\section{References}

[1] V. N. Moiseyev, Titanium Alloys. Russian aircraft and aerospace applications. London-New YorkSingapore: Taylor \& Francis Group, 2006.

[2] I. V. Gorynin, and B. B. Chechulin, Titan v mashinostroenii [Titan in mechanical engineering]. Moscow, Russia: Mashinostroenie Publ., 1990. [in Russian].

[3] F. Hideki, T. Kazuhiro, Y. Yoshito, "Application of titanium and its alloys for automobile parts," in Nippon Steel Technical Report, no. 88, 2003, pp. 70-75.

[4] A. T. Pichuhin., et al., "Influence of the Phase-Structural State of the Surface Layers on the Mechanical Properties of VT1-0 Titanium Alloy", Materials Science, vol. 47, no. 5, pp. 670-676, 2012.

[5] G. Lutjering, and J. C. Williams, Titanium alloys. Verlag-Berlin-Heidelberg: Springer Publ., 2007.

[6] S. G. Glazunov, Titanivye splavy. Konstrukcionnye titanovye splavy [Titanium alloys. Structural titanium alloys]. Moscow, Russia: Metallurgiya Publ., 1974. [in Russian].

[7] E. M. Lazarev, Z. I. Kornilova, and N. M. Fedorchuk, Okisleniya ninatovikh splavov [Oxidation of titanium alloys]. Moscow, Russia: Nauka Publ., 1985. [in Russian].

[8] E. Fromm and E. Gebkhardt, Gazy i uglerod v metallakh [Gases and carbon in metals]. Moscow, Russia: Metallurgiya Publ., 1980. [in Russian].

[9] A. I. Gusev, "Fazovyye ravnovesiya. Fazy i soyedineniya v sisteme Ti-C" ["Phase equilibrium. Phases and compounds in the Ti-C system"], Uspekhi khimii [Advances in Chemistry], vol. 71, no. 6, pp. 507-532, 2002. [in Russian]. 
Kinetics of High-Temperature Interaction of Titanium Alloys with a Carbon-Containing ... 39

[10] H. Okamoto, "C-Ti (Carbon-Titanium)", Journal of Phase Equilibria and Diffusion, vol. 27, no. 3, pp. 306-307, 2006.

[11] E. Storms, Tugoplavkiye karbidy [Refractory carbides]. Moscow, Russia: Atomizdat Publ., 1974. [in Russian].

[12] V. S. Shveykin, et al., Soyedineniya peremennogo sostava i ikh tverdyye rastvory [Compounds of variable composition and their solid solutions]. Sverdlovsk, Russia: UNU AN SSSR Publ., 1984. [in Russian].

[13] E. K. Molchanova, Atlas diagramm sostoyaniya titanovykh splavov [Atlas of state diagrams of titanium alloys]. Moscow, Russia: Mashinostroyeniye Publ., 1964. [in Russian].

[14] Kh. D. Goldshmidt, Splavy vnedreniya [Alloys of the interstitial], vols. 1-2. Moscow, Russia: Mir Publ., 1971. [in Russian].

[15] G. V. Zemkov, and R. L. Kogan, Mnogokomponentnoye diffuzionnoye nasyshcheniye metallov i splavov [Multicomponent diffusion saturation of metals and alloys]. Moscow, Russia: Metallurgy Publ., 1978. [in Russian].

[16] B. F. Ormont, Soyedineniya peremennogo sostava [Compounds of variable composition]. Leningrad, Russia: Khimiya Publ., 1969. [in Russian].

[17] V. P. Elyutin, et al., Vzaimodeystviye okislov metallov z uglerodom [Interaction of metal oxides with carbon]. Moscow, Russia: Metallurgy Publ., 1976. [in Russian].

[18] V. D. Kalner, et al., "Struktura i svoystva okislennykh karbonitridnykh pokrytiy" ["Structure and properties of oxidized carbonitride coatings"], MiTOM [Metallurgy and heat treatment], vol. 3, pp. 54-58, 1990. [in Russian].

[19] I. Dahan, et al., "The development of a functionally graded TiC-Ti multilayer hard coating", Surf. And Coat. Technol., vol. 137, pp. 111-115, 2011.

[20] N. G. Boriskina, "Vliyaniye dlitelnogo oksidirovaniya na korrozionnuyu stoykost i mekhanicheskiye svoystva VT1-0" ["The effect of prolonged oxidation on the corrosion resistance and mechanical properties of VT1-0"], in Titan dlya narodnoho hozyaystva [Titan for national economy]. Moscow, Russia: Nauka Publ., 1973, pp. 255-262. [in Russian].

[21] H. Dong, W. Shi, and T.H. Bell, "Potential of improving tribological performance of UHMWPE by engineering the Ti6V4Al counterfaces", Wear, vols. 225-229, pp. 146-153, 1999.

[22] V. A. Zhilyayev, et al., "Issledovaniye protsessa okisleniya oksikarbidov titana na vozdukhe" ["Investigation of oxidation of titanium oxycarbides in air"], Neorganicheskiye materialy [Inorganic materials], vol. 10, no. 5, pp. 1006-1010, 1974. [in Russian].

[23] I. Polyakova, and Th. Hubert, "Thermal stability of TiN thin films investigated by DTG/DTA", Surface and Coating Technology, vol. 141, pp. 55-61, 2001.

[24] A. A. Ilyin, B. A. Kolachev, and I. S. Polkin, Titanovyye splavy. Sostav. Struktura. Svoystva [Titanium alloys. Composition. Structure. Properties]. Moscow. VILS-MATI Publ., 2009. [in Russian]. 